\title{
The selective species in ethylene epoxidation on silver
}

Travis E. Jones ${ }^{1,}{ }^{*}$, Regina Wyrwich ${ }^{2}$, Sebastian Böcklein ${ }^{2,+}$, Emilia A. Carbonio ${ }^{\prime,}$, Mark T. Greiner ${ }^{1}$, Alexander Yu. Klyushin ${ }^{1,3}$, Wolfgang Moritz ${ }^{5}$, Andrea Locatelli, Tefvik O. Menteş', Miguel A. Niño ${ }^{6}$, Axel Knop-Gericke ${ }^{1}$, Robert Schlögl ${ }^{1}$, Sebastian Günther ${ }^{4}$, Joost Wintterlin², Simone Piccinin ${ }^{7}$

1 Inorganic Chemistry Department, Fritz-Haber-Institute, Faradayweg 4-6, 14195 Berlin (Germany). 2 Department Chemie, Ludwig-Maximilians-Universität München, Butenandtstr. 5-13, 81377 Munich (Germany). 3 Helmholtz-Zentrum Berlin für Materialien und Energie GmbH, BESSY II, Albert-Einstein-Straße 15, 12489 Berlin, Germany. 4 Chemie Department, Technische Universität München, Lichtenbergstr. 4, 85748 Garching (Germany). 5 Department of Earth and Environmental Sciences, Ludwig-Maximilians-Universität München, Theresienstrasse 41, 80333 Munich, Germany. 6 Elettra-Sincrotrone Trieste S.C.p.A. S.S. 14 - km 163,5 in AREA Science Park, 34149 Basovizza, Trieste, Italy. 7 CNR-IOM DEMOCRITOS, c/o SISSA, Via Bonomea 265, 34136 Trieste (Italy). †Current Address: Clariant Produkte (Deutschland) GmbH, Waldheimer Str. 13, 83052 Bruckmühl (Germany)

*trjones@fhi-berlin.mpg.de

TOC graphic

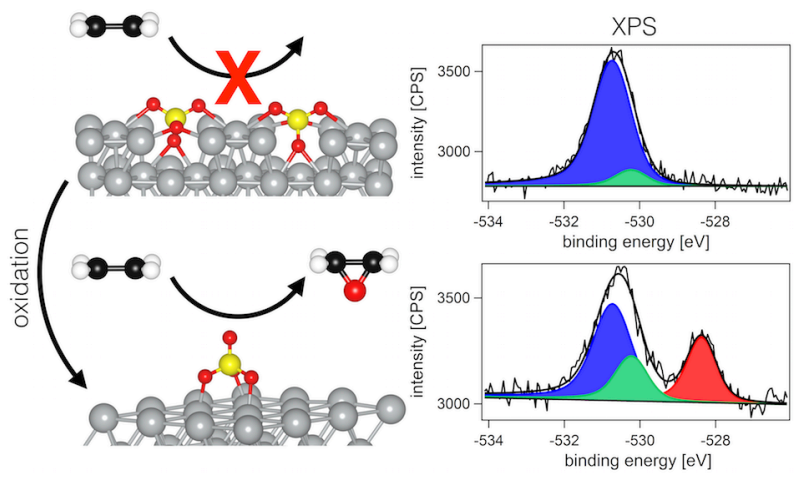




\begin{abstract}
Silver's unique ability to selectively oxidize ethylene to ethylene oxide under an oxygen atmosphere has long been known. Today it is the foundation of ethylene oxide manufacturing. Yet, the mechanism of selective epoxide production is unknown. Here we use a combination of UHV and in situ experimental methods along with theory to show that the only species that has been shown to produce ethylene oxide, the so-called electrophilic oxygen appearing at $530.2 \mathrm{eV}$ in the $0 \mathrm{1s}$ spectrum, is the oxygen in adsorbed $\mathrm{SO}_{4}$ $\left(\mathrm{SO}_{4, \mathrm{ad}}\right)$. This adsorbate is part of a $2 \mathrm{D} \mathrm{Ag} / \mathrm{SO}_{4}$ phase, where the nonstoichiometric surface variant, with a formally $\mathrm{S}(\mathrm{V}+)$ species, facilitates selective transfer of an oxygen atom to ethylene. Our results demonstrate the significant and surprising impact of a trace impurity on a well-studied heterogeneously catalyzed reaction.
\end{abstract}

Keywords Ethylene epoxidation, electrophilic oxygen, silver, partial oxidation, XPS

\title{
Introduction
}

The direct epoxidation of ethylene to ethylene oxide (EO) over silver is one of the most important heterogeneously catalyzed reactions practiced in industry ${ }^{1-6}$. In it, an oxygen atom from $\mathrm{O}_{2}$ is added across the $\mathrm{C}-\mathrm{C}$ double bond of ethylene. This simplicity makes ethylene epoxidation a tractable means of studying selectivity in heterogeneous catalysis, where selectivity refers to the fact that EO is just one potential reaction product. The selectivity to be explained is amazing; on clean silver it is near $50 \%{ }^{1-4}$ and can exceed $80 \%$ with the use of 
promoters $^{1-7}$. Yet, a mechanistic understanding consistent with experimental data has been lacking since the 1931 discovery of the reaction ${ }^{1-4}$. The first plausible models dealing with selectivity appeared in the 1940 s, postulating a special form of adsorbed oxygen selectively oxidizes ethylene to E0 ${ }^{1-3}$. This species became known as electrophilic oxygen $\left(\mathrm{O}_{\mathrm{elec}}\right)^{3}$. Vigorous debate over two models of $\mathrm{O}_{\text {elec }}$-atomic or molecular oxygen-dominated the literature 1-3,8-11 $^{-1}$ until $\mathrm{O}_{\text {elec }}$ was found under vacuum above the $\mathrm{O}_{2}$ desorption temperature ${ }^{9-12}$, igniting interest in the chemistry of adsorbed atomic oxygen. With the aid of DFT calculations, such studies led to development of a mechanism wherein ethylene is predicted to react with adsorbed atomic oxygen to form an oxametallacycle (OMC) intermediate ${ }^{14-16}$. And while oxygen on reconstructed silver surfaces was found to selectively produce $\mathrm{CO}_{2}$ through this mechanism ${ }^{16}$, when the reacting oxygen is adsorbed on an unreconstructed surface EO is predicted to be formed non-selectively ${ }^{14,15}$. Recently, however, this type of adsorbed atomic oxygen was shown to be incompatible with measurements of $\mathrm{O}_{\text {elec }}{ }^{17-21}$.

Although $\mathrm{O}_{\text {elec }}$ readily forms under the oxygen chemical potential required for epoxidation ${ }^{22-24}$, it is challenging to generate it under clean conditions ${ }^{9-13}$ those in which no gas-phase impurities are introduced. Thus, unlike the nucleophilic oxygen $\left(\mathrm{O}_{\text {nuc }}\right)$, active only in combustion ${ }^{13,17}$ - where established ultra-high vacuum (UHV) preparations allowed its structure to be solved $25-27$ surfaces active in EO production during temperature programmed reaction (TPR) have only been prepared through extensive oxidation at $c a .500 \mathrm{~K}^{9,10}$ or exposure to epoxidation conditions ${ }^{11-13}$. While these studies demonstrated the EO-selective species seen in TPR is responsible for catalytic epoxidation ${ }^{10}$, they offered only puzzling structural insight. For instance, experiments relying on 
oxidative preparations revealed such treatments lead to significant dissolution of $\mathrm{O}$ into $\mathrm{Ag}$ and that $\mathrm{O}_{\text {elec }}$ only forms in the presence of both $\mathrm{O}_{\text {nuc }}$ and dissolved $\mathrm{O}$ $\left(\mathrm{O}_{\text {dis }}\right)^{9,10}$. Unfortunately such severe treatment leaves little chance of uncovering the structure of the EO-selective species.

A method of preparing dissolved $0, \mathrm{O}_{\text {nuc }}$, and $\mathrm{O}_{\text {elec }}$ on $\mathrm{Ag}(111)$ single crystals under UHV was, however, recently developed ${ }^{18,19}$. In it, $\operatorname{Ag}(111)$ samples were treated by repeated $\mathrm{NO}_{2}$ oxidation/annealing cycles, leading to the cyclic formation and decomposition of an oxygen species with an 0 1s binding energy (BE) of $528.3 \mathrm{eV}\left(\mathrm{O}_{\text {nuc }}\right)$, and the parallel, slower enrichment of a second oxygen species on the surface at a BE of $530.7 \mathrm{eV}$. The formation of the $530.7 \mathrm{eV}$ species resembles a precipitation, involving segregation of $\mathrm{O}_{\text {dis }}$ to the surface. Surprisingly, under clean conditions the $530.7 \mathrm{eV}$ species forms an ordered structure giving rise to a $(7 \times \sqrt{3})$ rect low energy electron diffraction (LEED) pattern ${ }^{19}$.

Herein we use a combination of experimental and computational approaches to show the $(7 \times \sqrt{3})$ rect phase with a $530.7 \mathrm{eV} 01 \mathrm{~s} \mathrm{BE}$ is the parent phase of $\mathrm{O}_{\text {elec }}$ prepared by thermal oxidation. We go on to show this $\mathrm{O}_{\text {elec }}$ forms spontaneously under reaction conditions and its coverage correlates with EO production.

\section{Results}

\section{Electronic and atomic structure}

To solve the structure of the $(7 \times \sqrt{3})$ rect surface phase we turned to density functional theory (DFT), LEED $I / V$, and XPS by first noting that only covalently bound $\mathrm{O}$ has $\mathrm{ca} .530 \mathrm{eV} 0$ 1s BE${ }^{17}$. Thus, we considered $\mathrm{O}$ bound to common impurities; only S-a ubiquitous contaminant of ethylene ${ }^{28}$ and $\mathrm{Ag}^{29}-$ 
explains the observed properties. XPS/LEED confirms that a $(7 \times \sqrt{3})$ rect reconstructed surface phase contains $S$ with a $S: 0$ ratio of $c a$. 1:4, Figure 1 -note no $\mathrm{S}$ was visible in XPS when the oxidative preparation began. DFT calculations reveal the lowest energy $\mathrm{Ag} / \mathrm{SO}_{4}$ structure with $(7 \times \sqrt{3})$ rect periodicity has an $\mathrm{Ag}_{9}\left(\mathrm{SO}_{4}\right)_{3}$ stoichiometry, Figure 1. The coordinates from the DFT relaxation were used as the starting point of a LEED $I / V$ analysis. The model obtained from this analysis, after an extended optimization procedure, was identical to the DFT model, except for minor displacements in the atomic positions. In the unit cell, three $\mathrm{SO}_{4}$ moieties are bound to $9 \mathrm{Ag}$ atoms in the top layer (the bare surface would contain 14 first layer Ag atoms in the cell), and 6 of these 9 atoms are strongly displaced from their bulk positions, i.e., the surface is reconstructed.
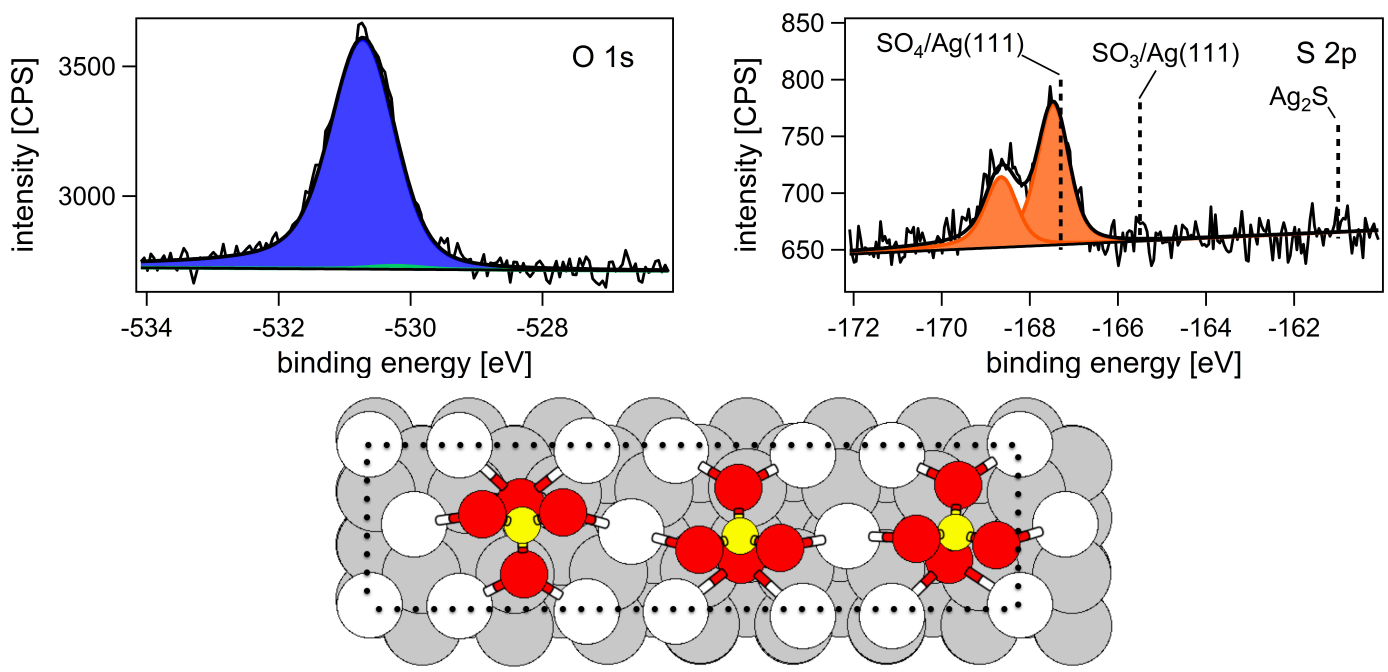

Figure 1: 01 s and $S 2 p$ spectra of the $(7 \times \sqrt{3})$ rect reconstruction; $S 2 p_{3 / 2}$ reference BEs (dashed lines) ${ }^{30,31}$. The surface phase structure computed with DFT (bottom). White circles show $\mathrm{Ag}^{\delta+}$ atoms in the reconstructed layer, grey $\mathrm{Ag}^{0}$ in the lower layers, red 0 , and yellow $\mathrm{S}$.

With the structure of the $(7 \times \sqrt{3})$ rect reconstruction solved, we examined the core-level BEs of its constituent atoms to gain insight into its electronic structure and forge connections with previous measurements $12,13,22,23$. The average computed $01 \mathrm{~s}\left(\mathrm{~S} 2 \mathrm{p}_{3 / 2}\right) \mathrm{BE}$ is $530.5 \mathrm{eV}(167.3 \mathrm{eV})$, compared to the measured $530.7 \mathrm{eV}(167.5 \mathrm{eV})$, differences within the error typically associated 
with computed binding energies ${ }^{16}$. The computed $\mathrm{Ag} 3 \mathrm{~d}_{5 / 2} \mathrm{BE}$ of the Ag atoms in the reconstructed layer is $0.4 \mathrm{eV}$ less than that of bulk $\mathrm{Ag}$, indicating $\mathrm{Ag}^{\delta+}$ character.

Oxidation of an uncovered $\operatorname{Ag}(111)$ surface is known to form a $p(4 \times 4)$-0 phase, a reconstruction with a stoichiometry of the first layer of $\mathrm{Ag}_{12} \mathrm{O}_{6}{ }^{25-27}$ where the $p(4 \times 4)$ structure is reconstructed with $12 \mathrm{Ag}$ atoms per unit cell (instead of the bare surface's 16) and 60 atoms, corresponding to an $\mathrm{Ag}_{12} \mathrm{O}_{6}$ stoichiometry. The oxygen atoms contained in this phase are $\mathrm{O}_{\text {nuc }}{ }^{16}$. On a surface partially covered by the $(7 \times \sqrt{3})$ rect structure ${ }^{18,19}$, the rest is empty $\operatorname{Ag}(111)$, this oxidation can be described by two limiting reactions:

$$
3 \mathrm{O}_{2 \text {,gas }}+12 \mathrm{Ag}_{\text {surface }} \rightleftharpoons \mathrm{Ag}_{12} \mathrm{O}_{6} \text {. }
$$

and

$$
9 \mathrm{O}_{2, \text { gas }}+4 \mathrm{Ag}_{9}\left(\mathrm{SO}_{4}\right)_{3} \rightleftharpoons 3 \mathrm{Ag}_{12} \mathrm{O}_{6}+12 \mathrm{SO}_{4, \text { ad }} \text {. }
$$

In Equation 1, the empty portion of the surface reacts with oxygen to give the $p(4 \times 4)-0$ reconstruction, a process in which Ag atoms, mainly from step sites, are used to build the $p(4 \times 4)$-0 phase. The $(7 \times \sqrt{3})$ rect structure is unaffected by Equation 1. In Equation 2, the number of Ag atoms in a reconstruction $\left[\mathrm{Ag}_{9}\left(\mathrm{SO}_{4}\right)_{3}\right.$ or $\left.\mathrm{Ag}_{12} \mathrm{O}_{6}\right]$ are fixed. The resulting adatom competition forces the $(7 \times \sqrt{3})$ rect reconstruction to be lifted in order to liberate the Ag atoms used to form the $p(4 \times 4)$-0 phase. This process transforms the $(7 \times \sqrt{3})$ rect reconstruction into a phase with $\mathrm{SO}_{4}$ moieties on the unreconstructed $\mathrm{Ag}$ surface- $-\mathrm{SO}_{4, \text { ad. }}$ To see under which conditions these limiting reactions can occur we must compute the change in surface Gibbs free energy associated with each, which we denote $\Delta \gamma_{1}$ and $\Delta \gamma_{2}$ for Equation 1 and 2, respectively. 
Using the facts that the entropy terms of the solid phases tend to cancel and that the $p V$ terms are negligible allows us to compute $\Delta \gamma_{1}$ and $\Delta \gamma_{2}$ with DFT total energies and gas-phase thermochemistry data ${ }^{32}$. Assuming both reactions go to completion, see SI for details, we find $\Delta \gamma_{1}$ and $\Delta \gamma_{2}$ depend both on the oxygen chemical potential $\left(\Delta \mu_{0}\right)$ and amount of free surface available. Equation 1 has a trivial dependence on free surface area. In the case of Equation 2, however, the dependence is complicated by the fact that the energy of $\mathrm{SO}_{4, \text { ad }}$ changes with its coverage, $\Theta_{\mathrm{SO}_{4}}$. Thus, $\Delta \gamma_{2}$ depends on $\Theta_{\mathrm{SO}_{4}}$.

To see how this coverage dependency of $\Delta \gamma_{2}$ is manifest we generated a series of phase diagrams with varying $\Theta_{\mathrm{SO}_{4}}$, see Figure 2 . We find that for $\Theta_{\mathrm{SO}_{4}} \gtrsim 1 / 5 \mathrm{ML}, \mathrm{SO}_{4}$, ad is spontaneously formed ( $\Delta \gamma<0$ ) only at oxygen chemical potentials high enough to form bulk $\operatorname{Ag}_{2} \mathrm{O}, \Delta \mu_{0}=\Delta H_{A g_{2} O}^{f}$, see the solid blue line in Figure 2 . In contrast, formation of the $p(4 \times 4)$-0 reconstruction on the same surface becomes spontaneous at $\Delta \mu_{0} \gtrsim-0.6 \mathrm{eV}$ (solid black line) $-\mathrm{T} \lesssim 600 \mathrm{~K}$ at 1 atm $\mathrm{O}_{2}$ pressure. Once $\Theta_{\mathrm{SO}_{4}}$ drops below ca. 1/9 ML however, Equation 2 also becomes spontaneous at $\Delta \mu_{0} \gtrsim-0.6 \mathrm{eV}$ (dashed blue line), though it is only metastable as formation of the $p(4 \times 4)$-0 reconstruction through Equation 1 is still energetically favored on the same surface (dashed black line). 


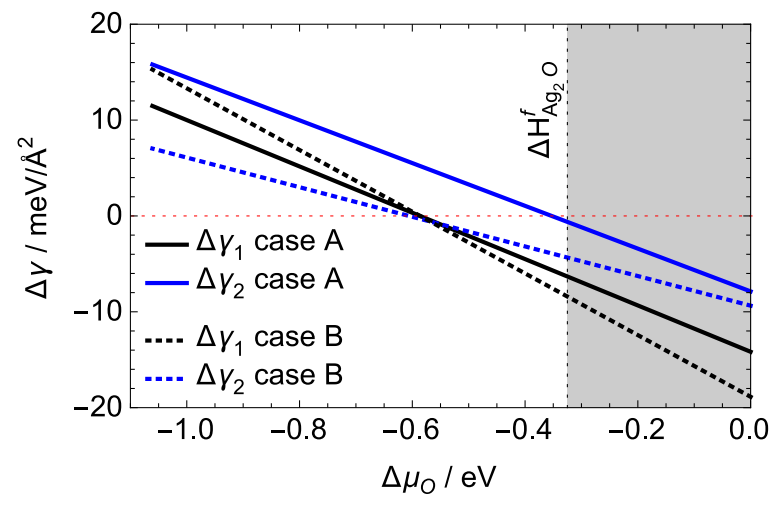

Figure 2: Change in surface free energy associated $p(4 \times 4)$-0 formation through Equation 1 (black lines) and Equation 2 (blue lines) described in the text, where $\Delta \mu_{0}=\frac{1}{2}\left(\mu_{O_{2}}-H_{O_{2}}\right)$. The experimental value of $\Delta H_{\mathrm{Ag}_{2} \mathrm{O}}^{f}$ extrapolated to $0 \mathrm{~K}^{33}$ is indicated. The lines were computed for two different fractions of free surface. In case A (solid lines) reaction (2) gives an $\mathrm{SO}_{4, \text { ad }}$ phase with $\Theta\left(\mathrm{SO}_{4, \mathrm{ad}}\right)=1 / 5 \mathrm{ML}$ plus the corresponding $p(4 \times 4)$-0 area, and reaction (1) takes place on a surface with the same fraction of free area but only gives the $p(4 \times 4)$-0 phase. Case B (broken lines) is analogous but uses $\Theta\left(\mathrm{SO}_{4, \mathrm{ad}}\right)=1 / 9 \mathrm{ML}$. The DFT total energy of the $\mathrm{SO}_{4, \text { ad }}$ phases was defined using linear interpolation of the value at three coverages, see Figure S4.

Figure 2 shows oxidation of a surface partially covered in the $(7 \times$ $\sqrt{3})_{\text {rect- }} \mathrm{SO}_{4}$ phase can lead to the formation of a metastable phase of $\mathrm{SO}_{4}$, ad. If present, our calculations reveal this $\mathrm{SO}_{4}$, ad could be distinguished from the parent $(7 \times \sqrt{3})$ rect-SO 4 phase by way of XPS. The computed $\mathrm{Ag} 3 \mathrm{~d}_{5 / 2} \mathrm{BE}$ of a surface with $\mathrm{SO}_{4, \text { ad }}$ indicates three $\mathrm{Ag}^{\delta+}$ sites bond to $\mathrm{SO}_{4, \mathrm{ad}}$-making $\mathrm{S}$ formally $\mathrm{V}+$, consistent with the $166.7 \mathrm{eV}$ computed S $2 \mathrm{p}_{3 / 2} \mathrm{BE}$. Its average computed $01 \mathrm{~s}$ $\mathrm{BE}$ is $0.7 \mathrm{eV}$ less than the $\mathrm{O}$ in the $(7 \times \sqrt{3})$ rect-SO $\mathrm{SO}_{4}$ phase, Table S1.

The 0 1s spectrum measured after oxidation of the $(7 \times \sqrt{3})$ rect reconstruction confirms the appearance of $\mathrm{SO}_{4, \text { ad }}$ and $\mathrm{O}_{\text {nuc }}$, Figure 3. $\mathrm{O}_{\text {nuc }}$ gives the 0 1s peak at $528.4 \mathrm{eV}^{12,13,16,22,23}$. The peak near $530 \mathrm{eV}$ is broadened due to the appearance of a new peak on the low $B E$ side of the $530.7 \mathrm{eV}$ peak. Previous in situ work unambiguously showed this new species is a $530.2 \mathrm{eV}$ component ${ }^{18}$ consistent with $\mathrm{O}_{\text {elec }}{ }^{12,13,22-24}$ — whose intensity increase is triggered by the formation of the $p(4 \times 4)-0$ phase. This BE is in good agreement with that 
computed for $\mathrm{SO}_{4, \text { ad }}$ on the unreconstructed surface, while the remaining $(7 \times \sqrt{3})$ rect- $\mathrm{SO}_{4}$ phase appears at $530.7 \mathrm{eV}$. The $\mathrm{S}: 0$ ratio of the total intensity of the $530.2 \mathrm{eV}$ and $530.7 \mathrm{eV}$ components remains 1:4 (see Table S2). The 530.2 $\mathrm{eV}$ component can then be assigned to $\mathrm{SO}_{4, \mathrm{ad}}$ on the unreconstructed surface.
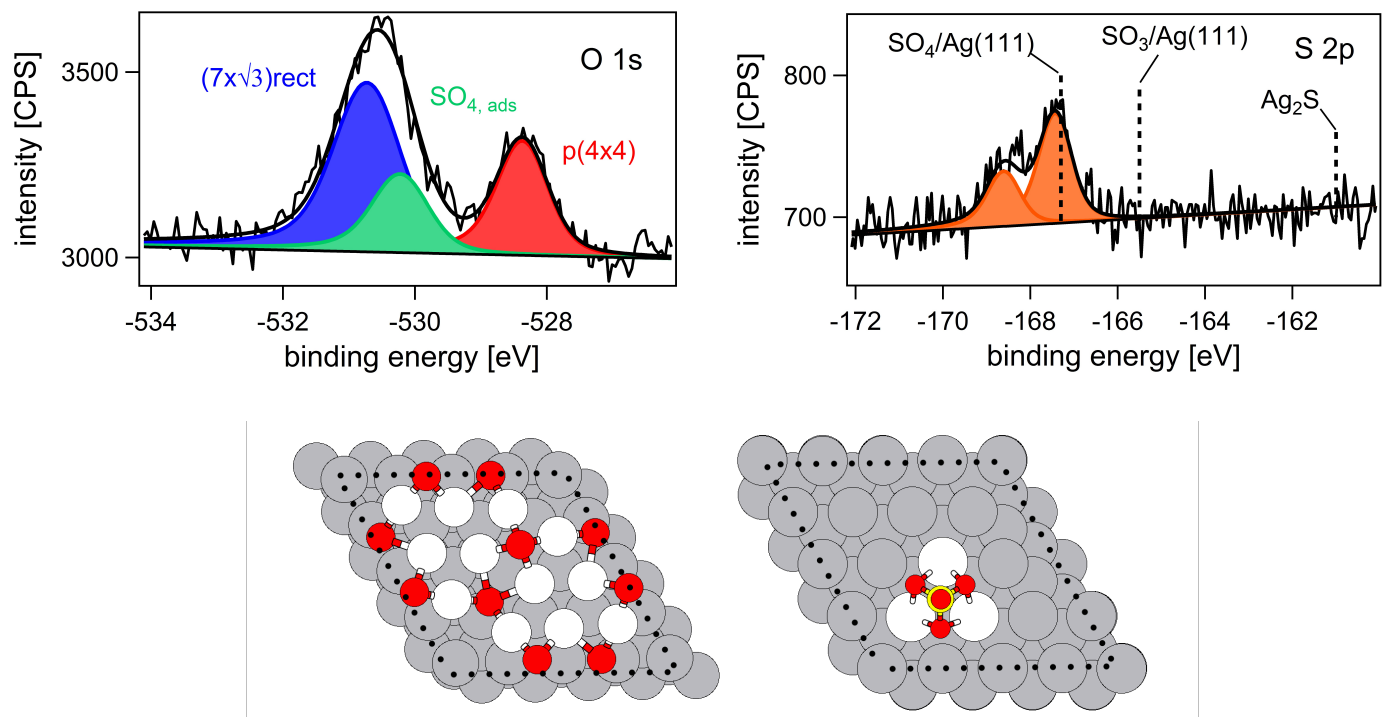

Figure 3: $01 \mathrm{~s}$ and $\mathrm{S} 2 \mathrm{p}$ spectra- $\mathrm{S} 2 \mathrm{p}_{3 / 2}$ reference BEs (dashed lines) ${ }^{30,31}$-of the reconstructed $\mathrm{SO}_{4}$ phase, prepared as in Figure 1, after oxidation with $270 \mathrm{~L} \mathrm{NO}_{2}$ at $500 \mathrm{~K}$. Structures of the $p(4 \times 4)$ - 0 phase (bottom left) and $\mathrm{SO}_{4, \text { ad }}$ (bottom right). Coloring matches Figure 1.

The reason for the incomplete conversion of the reconstructed $\mathrm{SO}_{4}$ phase into the unreconstructed one is clear when considering the preceding thermodynamic analysis. Formation of the $p(4 \times 4)-0$ phase through Equation 1 is thermodynamically favored over its production through Equation 2. However, there are also kinetic effects. The $530 \mathrm{eV}$ oxygen has been shown to decorate the steps $^{18}$, so that, with increasing initial coverage of the $530.7 \mathrm{eV}$ oxygen the steps-which act as sources for Ag atoms-become blocked. As Equation 1 is based on accessible steps, the thermodynamically less favored Equation 2 then becomes dominant. This competition for Ag adatoms explains why under UHV conditions dense adsorbate phases are required to populate a significant amount of the $530.2 \mathrm{eV}$ oxygen species, because dilute phases always provide access to 
$\mathrm{Ag}$ adatoms at step edges, thereby preventing formation of the metastable phase. It also explains why the $530.2 \mathrm{eV} 0$ 1s species does not appear as a pure phase in oxidative preparations.

\section{TPR activity}

With the spectroscopic properties of $\mathrm{SO}_{4, \text { ad }}$ determined to match those of $\mathrm{O}_{\text {elec, }}$ we turned to TPR to see if its chemical reactivity also does so. First the $\mathrm{SO}_{4}$ reconstruction was prepared on a $\mathrm{Ag}(111)$ single crystal as above, Figure 4 spectrum I. This surface was exposed to 0.1 mbar ethylene for 10 minutes at 298 $\mathrm{K}$ before evacuating to UHV. The surface was then heated at $0.8 \mathrm{~K} / \mathrm{s}$. Neither $\mathrm{CO}_{2}$ $(\mathrm{m} / \mathrm{z}=44 \mathrm{amu})$ or the $\mathrm{m} / \mathrm{z}=29 \mathrm{amu}$ fragment often assigned to a CHO fragment from E0 ${ }^{10,11,34}$ was observed in QMS. This inactivity is consistent with reports that, alone, the oxygen species with a BE of $c a .530 \mathrm{eV}$ is inactive in TPR with ethylene ${ }^{9-12}$.
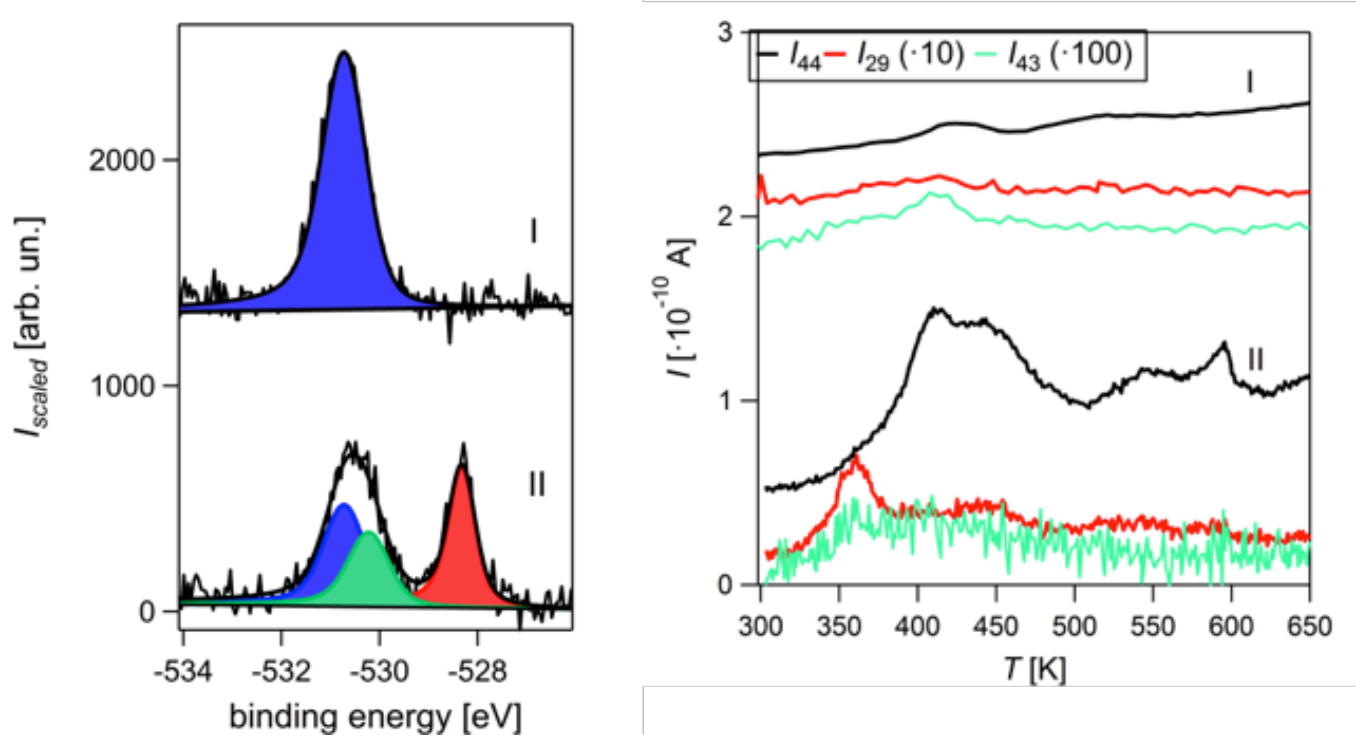

Figure 4: $01 \mathrm{~s}$ (left) and TPR (right) spectra of the $(7 \times \sqrt{3})$ rect reconstruction (I) and the surface active in ethylene epoxidation (II). $\mathrm{CO}_{2}$ (EO) production leads to $\mathrm{m} / \mathrm{z}=44 \mathrm{amu}(\mathrm{m} / \mathrm{z}=29$ amu and $\mathrm{m} / \mathrm{z}=43$ ).

In a second experiment we prepared $\mathrm{SO}_{4, \text { ad }}$ and $\mathrm{O}_{\text {nuc }}$ by $\mathrm{NO}_{2}$-dosing on the $\mathrm{SO}_{4}$-reconstructed surface, Figure 4 spectrum II. This surface was exposed to the 
aforementioned ethylene treatment. Now both $\mathrm{m} / \mathrm{z}=29 \mathrm{amu}$ and $44 \mathrm{amu}$ are seen during TPR. The $c a .360 \mathrm{~K}$ desorption temperature for the $\mathrm{m} / \mathrm{z}=29$ fragment-ca. $1 \mathrm{eV}$ apparent activation energy for desorption from a first order Redhead analysis ${ }^{11}$ —is consistent with previous measurements of an $\operatorname{Ag}(111)$ surface active in EO production during TPR ${ }^{11}$. It should be noted however, that $\mathrm{m} / \mathrm{z}=29$ is not unique to $\mathrm{EO}$ due to cross-sensitivities with ${ }^{13} \mathrm{CO}, \mathrm{H}_{2}{ }^{13} \mathrm{C}={ }^{12} \mathrm{CH}_{2}$, and $\mathrm{AcH}^{34}$. We were able to eliminate the former two possibilities by confirming $\mathrm{C}_{2} \mathrm{H}_{3} \mathrm{O}(\mathrm{m} / \mathrm{z}=43)$ desorbs at the same temperature (Figure 4) and can rule out $\mathrm{AcH}$ because it is converted entirely to $\mathrm{CO}_{2}$ in the presence of the $p(4 \times 4)-0$ phase $^{12}$. Thus, we assign the desorption signal at $c a .360 \mathrm{~K}$ to an E0 fragment, demonstrating that oxidizing the $(7 \times \sqrt{3})$ rect-reconstructed surface produces the EO-selective species active in TPR.

Earlier isotope labeling studies showed only 0 with an 0 1s BE of $c a .530$ $\mathrm{eV}$ is active in $\mathrm{EO}$ production ${ }^{13}$, which, in the new model, implies $\mathrm{SO}_{4, \text { ad }}$ is the EOselective species. To understand why, we computed the minimum energy paths (MEPs) for epoxidation on the reconstructed and unreconstructed $\mathrm{SO}_{4}$ phases.

The calculations reveal ethylene adsorbs on surfaces with both the $(7 \times$ $\sqrt{3})$ rect $-\mathrm{SO}_{4}$ reconstruction and $1 / 16 \mathrm{ML} \mathrm{SO}_{4, \text { ad }}$ with $E_{a d}=0.61 \mathrm{eV}$ and $0.21 \mathrm{eV}$, respectively. However, EO formation on the reconstruction is highly activated, $1.8 \mathrm{eV}$ relative to adsorbed $\mathrm{C}_{2} \mathrm{H}_{4}$; whereas the activation energy $\left(E_{a}\right)$ to EO formation from $\mathrm{O}$ in $\mathrm{SO}_{4, \text { ad }}$ is only $0.96 \mathrm{eV}$ relative to adsorbed ethylene.

In the case of $\mathrm{SO}_{4, \text { ad, }}$ ethylene reacts to form the intermediate in state 3 of Figure 5 in a near thermoneutral process (see Table S4; Tables S5-S7 for results with dispersion corrections). This intermediate can decompose into EO and $\mathrm{AcH}$ - the first step towards total oxidation ${ }^{14-16}$ — through different mechanisms. 
AcH formation follows a zwitterionic pathway, state 4 of Figure 5, with an $E_{a}$ of $1.35 \mathrm{eV}$. Unlike this ionic transition state, which is insensitive to spinpolarization, EO production is accomplished via a path with di-radical character ${ }^{35}$ - see state 6 of Figure 5 . In this case, the non-spin-polarized solution has a barrier similar to that found for $\mathrm{AcH}$ production, $1.22 \mathrm{eV}$. However, the adsorbed $\mathrm{C}_{2} \mathrm{H}_{4}-\mathrm{O}-\mathrm{SO}_{3}$ moiety allows spin-density to develop on the $\mathrm{C}$ and $\mathrm{O}$ atoms involved in ring closure, state 6 of Figure 5, which lowers the activation energy to $0.81 \mathrm{eV}$. This large difference in $E_{a}$ between the EO and AcH paths suggests the ability to localize spin-density makes $\mathrm{SO}_{4, \text { ad }}$ selective to the epoxide.

The $\mathrm{SO}_{3, \text { ad }}$ formed by oxygen transfer to ethylene in this process can be removed from the surface by disproportionation into $\mathrm{SO}_{4, \text { ad }}$ and $\mathrm{SO}_{2}$, with an estimated $E_{a}$ of $1.3 \mathrm{eV}^{30}$, or through reaction with ethylene. In the latter case, EO and $\mathrm{AcH}$ are predicted to be formed with computed activation energies of $1.2 \mathrm{eV}$, suggesting oxygen transfer from $\mathrm{SO}_{3 \text {,ad }}$ is slow and not selective to EO, see Figure S6 and Table S8. 


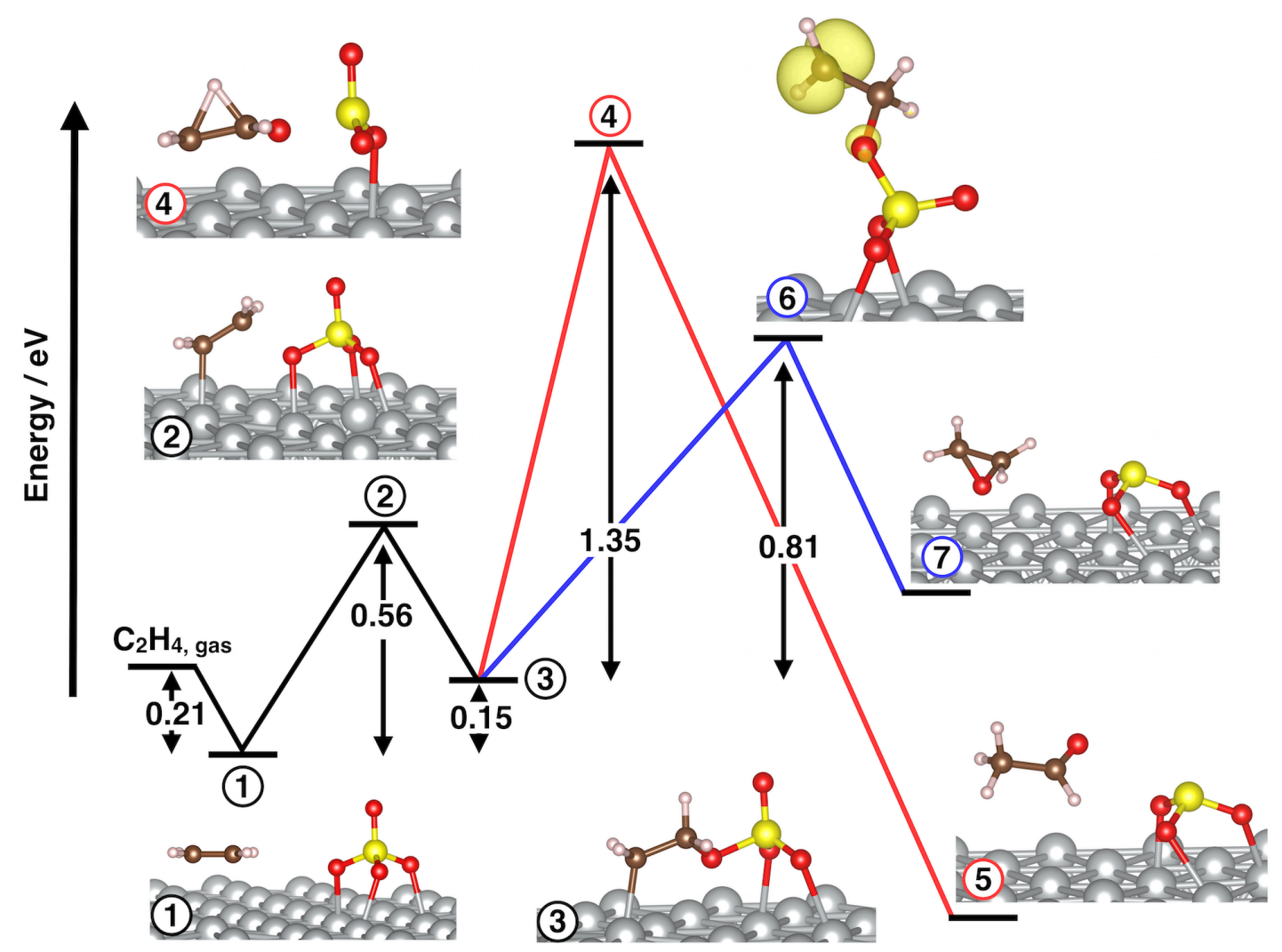

Figure 5: MEPs for the reaction of ethylene with $\mathrm{SO}_{4}$ on the unreconstructed surface with a spin density isosurface included for state 6. Only the forward $E_{a}$ 's are labeled at the transition statesstates 2, 4, and 6. See Table S4 for all energies. Paths to the adsorbed intermediate in state 3 are black, to EO blue, and to AcH red.

\section{In situ titration}

To further test this mechanism we turned to in situ XPS, where we measured the S $2 p$ spectra and product composition when a silver catalyst partially covered in $\mathrm{SO}_{4, \text { ad }}$ is exposed to ethylene at reaction temperature. The powder catalyst was first placed under epoxidation conditions-1:2 mixture of $\mathrm{C}_{2} \mathrm{H}_{4}: \mathrm{O}_{2}$ at 0.3 mbar and $503 \mathrm{~K}$-for ca. 100 mins. GC and PTRMS confirmed EO production. The gas-feed was then switched to ethylene while maintaining a total pressure of 0.3 mbar and temperature of $503 \mathrm{~K}$. A series of S $2 p$ spectra were measured during this ethylene titration, along with the PTRMS mass 45 
signal-which can capture rapid changes in EO production. (To verify the PTRMS signal was due to EO we simultaneously measured the gas-phase products with GC and saw no AcH production, see Table 1 for a list of analytical techniques used to detect EO.) The switch to a reducing atmosphere led to the growth of the predicted $\mathrm{SO}_{3, \text { ad }}$ intermediate, as indicated by the peak at $165.4 \mathrm{eV}$ in Figure 6; the computed binding energy is $165.0 \mathrm{eV}$. PTRMS shows the catalyst was still producing $\mathrm{EO}$ at this stage. As the time under 0.3 mbar ethylene increased all $\mathrm{SO}_{\mathrm{x}}$ species were titrated from the surface and EO production ceased. Based on the computed MEPs, Figure $\mathrm{S} 6$, we presume the $\mathrm{SO}_{3, \text { ad }}$ formed during titration further reacts with ethylene to yield a (partial) oxidation product and $\mathrm{SO}_{2}$. The latter will rapidly desorb at this temperature ${ }^{36}$.

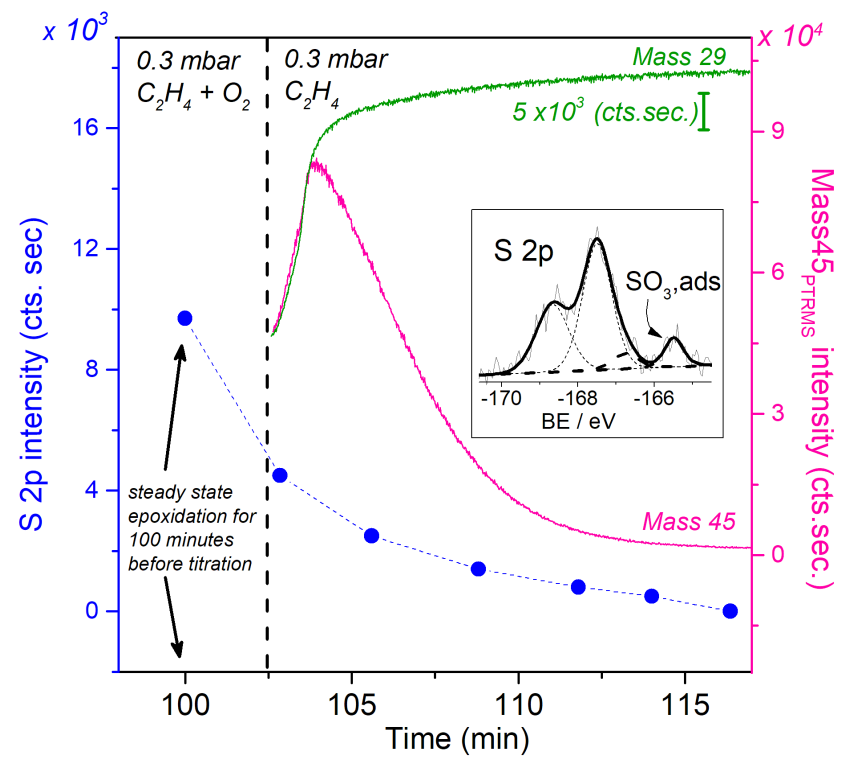

Figure 6: $\mathrm{S} 2 \mathrm{p}$ spectrum $(h v=750 \mathrm{eV})$ at the start of titration with 0.3 mbar ethylene at $503 \mathrm{~K}$ (inset). EO (mass 45) and ethylene (mass 29) pressure during ethylene titration as measured by PTRMS. The increase in ethylene pressure during the start of the titration causes a concomitant increase in EO pressure. The S 2p intensity measured at different is plotted for comparison. 
While ethylene titration indicates adsorbed $\mathrm{SO}_{4}$ remains active as a stoichiometric oxidant at epoxidation temperatures, earlier isotope labeling10 and in situ XPS studies ${ }^{22,23}$ showed the EO-selective species seen in TPR is also catalytically active. Hence, $\mathrm{SO}_{4, \text { ad }}$ should be reformed under epoxidation conditions by re-oxidation of $\mathrm{SO}_{3, \text { ad }}$. The low $E_{a}$ associated with $\mathrm{SO}_{3, \text { ad }}$ oxidation

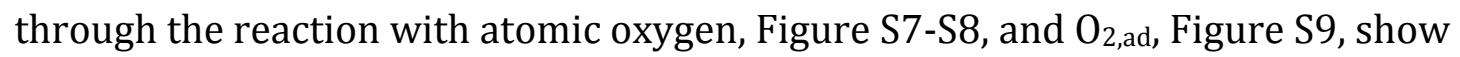
this is plausible. Oxidation through reaction with $\mathrm{O}_{2, \text { ad }}$, for instance, is activated by $0.66 \mathrm{eV}$, significantly less than the $>1 \mathrm{eV}$ associated with the competing $\mathrm{SO}_{3, \mathrm{ad}}$ reduction by ethylene, Figure S6. The calculations predict a non-vanishing steady-state coverage of $\mathrm{SO}_{4, \text { ad }}$ can be maintained under epoxidation conditions.

\section{In situ regeneration}

To see if $\mathrm{SO}_{4, \text { ad }}$ is (re)generated on a clean silver surface during epoxidation we returned to in situ XPS to first check if it is formed during epoxidation on a S-free catalyst surface. As in the case of the titration experiment, EO production was monitored by PTRMS to capture rapid changes in the product pressure while the $S 2 p$ spectrum was measured. To begin, a fresh $\mathrm{Ag}$ powder catalyst was cleaned by treatment in $0.3 \mathrm{mbar}_{2}$ at $873 \mathrm{~K}$ for 1 hour before cooling to room temperature. After cooling the $\mathrm{H}_{2}$ gas was replaced with a $1: 1$ mixture of $\mathrm{C}_{2} \mathrm{H}_{4}: \mathrm{O}_{2}$ while maintaining a total pressure of 0.3 mbar and a temperature of $273 \mathrm{~K}$. The S $2 p$ spectrum measured under these conditions revealed the near surface region was free from S contamination and no EO was observed in PTRMS, Figure 7A.

E0 production began upon heating the clean Ag powder to $523 \mathrm{~K}$ under the reaction gas mixture, and the $S 2 p$ spectrum revealed the concurrent appearance of $\mathrm{SO}_{4}$, Figure 7A. Continued epoxidation led to minor changes in the 
amount of S observed by XPS, and the $\mathrm{S} 2 \mathrm{p}$ spectrum showed $\mathrm{SO}_{4}$ was the only $\mathrm{S}$ species present under steady-state epoxidation, in agreement with the low

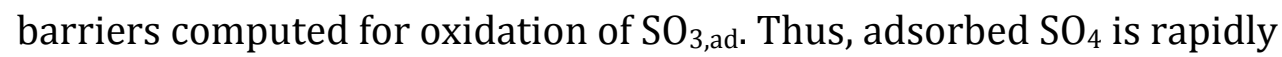
generated under epoxidation conditions and its coverage saturates, perhaps due to S dissolution and/or coverage effects (see Figure S4), confirming the TPR active species is formed and maintained under catalytic conditions.
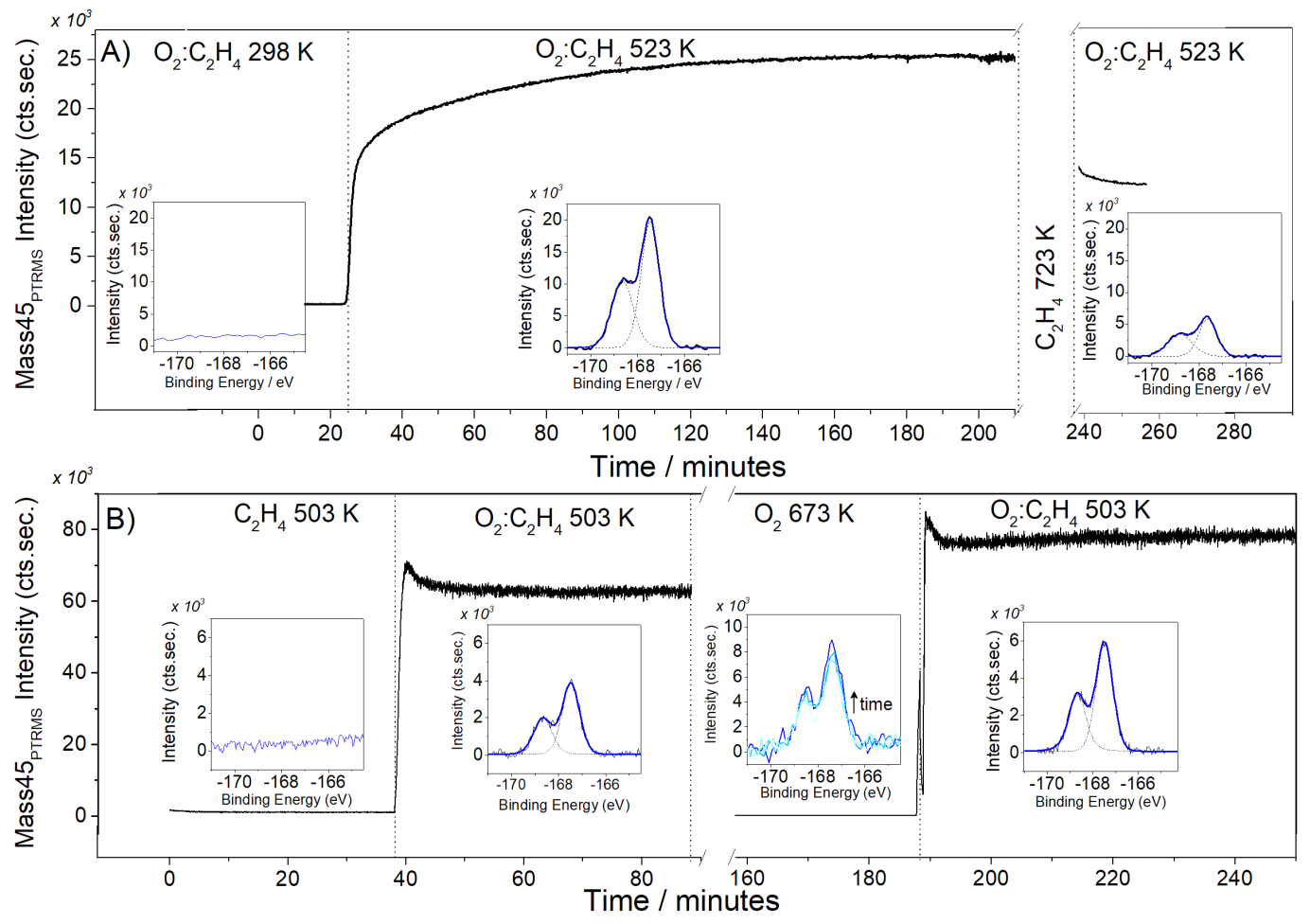

Figure 7: PTRMS (mass 45) showing the EO production from a Ag powder catalyst under various conditions (total pressure $0.3 \mathrm{mbar}$ ) with corresponding S $2 \mathrm{p}$ spectra inset. A) The catalyst was exposed to the reaction gas mixture at $298 \mathrm{~K}$ and then heated to $523 \mathrm{~K}$ to initiate the reaction. After 210 mins on stream the adsorbed $\mathrm{SO}_{4}$ formed during epoxidation was cleaned by ethylene titration before returning to the reaction gas mixture. S $2 \mathrm{p}$ spectra measured with $h v=355 \mathrm{eV}$. B) A Ag powder catalyst was held under ethylene at $503 \mathrm{~K}$ before introducing $\mathrm{O}_{2}$ to initiate the reaction. After 90 mins on stream more $\mathrm{S}$ was segregated to the surface under pure $\mathrm{O}_{2}$ before returning to the reaction gas mixture. S $2 \mathrm{p}$ spectra measured with $h v=390 \mathrm{eV}$. 
After operating the Ag powder catalyst for almost 200 mins we removed $\mathrm{SO}_{4}$ from the surface, confirmed with XPS, by ca. 30 mins of ethylene titration at $723 \mathrm{~K}$. The catalyst was then cooled to $523 \mathrm{~K}$ and oxygen was reintroduced to maintain a total pressure of 0.3 mbar in a $1: 1$ mixture of $\mathrm{C}_{2} \mathrm{H}_{4}: \mathrm{O}_{2}$. As before, PTRMS revealed the production of EO, and XPS showed the simultaneous appearance of $\mathrm{SO}_{4}$, Figure 7A. However, after regenerating the $\mathrm{S}$ phase there was less $\mathrm{SO}_{4}$ than before the ethylene titration and a two-fold decrease in the gasphase EO signal measured by PTRMS. This observation suggests catalytic EO production is linked to the coverage of the EO-selective species found in TPR.

To further test this link between EO production and adsorbed $\mathrm{SO}_{4}$ we cleaned a fresh Ag powder catalyst. In this case the clean catalyst was placed under 0.3 mbar $\mathrm{C}_{2} \mathrm{H}_{4}$ at $503 \mathrm{~K}$. No EO production was observed in PTRMS and the S 2p spectrum showed no evidence for S accumulation, Figure 7B. After $c a .40$ mins under ethylene the gas composition was switched to a 2:1 mixture of $\mathrm{O}_{2}: \mathrm{C}_{2} \mathrm{H}_{4}$ while maintaining the total pressure at 0.3 mbar and temperature at 503 $\mathrm{K}$. The addition of $\mathrm{O}_{2}$ at reaction temperature led to the immediate appearance of adsorbed $\mathrm{SO}_{4}$ and concomitant EO production, Figure 7B.

After ca. 50 mins of epoxidation ethylene was removed from the gasphase while maintaining a total pressure of 0.3 mbar. The temperature was also increased to $673 \mathrm{~K}$, which is above the desorption temperature of $\mathrm{O}_{\text {nuc }}$ but below that of the S phase ${ }^{18,19}$. As expected, PTRMS showed no EO production during this oxygen annealing, and the $S 2 p$ spectrum showed annealing led to an increase in the amount of adsorbed $\mathrm{SO}_{4}$, see Figure $7 \mathrm{~B}$, which may be due to the re-segregation of gas-phase S impurities dissolved during epoxidation. 
Returning to epoxidation conditions $-2: 1$ mixture of $\mathrm{O}_{2}: \mathrm{C}_{2} \mathrm{H}_{4}$ at $0.3 \mathrm{mbar}$ and $503 \mathrm{~K}$-after 90 mins of annealing in $\mathrm{O}_{2}$ led to the immediate appearance of EO in PTRMS, Figure 7B. In this case, the EO production was higher than before $\mathrm{O}_{2}$ annealing, and the increased coverage of the $\mathrm{S}$ phase induced by annealing was also maintained. Thus, adsorbed $\mathrm{SO}_{4}$ not only (re)forms on silver surfaces during epoxidation, but by increasing (decreasing) its coverage we see an increase (decrease) in EO production. Hence, it appears the steady-state EO production of an active catalyst may be correlated with the amount of adsorbed $\mathrm{SO}_{4}$-as expected if $\mathrm{SO}_{4, \text { ad }}$ remains active during catalytic epoxidation.

\section{Quantitative conversion}

We performed further in situ XPS experiments on Ag powder to verify the relationship between EO production and the coverage of adsorbed $\mathrm{SO}_{4}$. For this purpose we employed using a calibrated micro-GC to quantify the gas-phase EO and $\mathrm{CO}_{2}$ concentrations while the cleaned catalyst was exposed to a 2:1 mixture of $\mathrm{O}_{2}: \mathrm{C}_{2} \mathrm{H}_{4}$ at 0.3 mbar and $503 \mathrm{~K}$. The $\mathrm{S} 2 \mathrm{p}$ and $\mathrm{Ag} 3 \mathrm{~d}$ spectra were then measured using electrons of the same kinetic energy (220 eV) to allow the $\mathrm{SO}_{4} / \mathrm{Ag}$ ratio to be computed. As in the previous examples, $\mathrm{SO}_{4}$ appears once the reaction gas mixture is introduced at $503 \mathrm{~K}$, after which the amount of $\mathrm{SO}_{4}$ slowly increases with time on stream. Plotting the EO concentration against the measured $\mathrm{SO}_{4} / \mathrm{Ag}$ ratio, Figure 8, shows a concomitant increase in EO production, like that shown in Figures 7 and $\mathrm{S} 11$, and drop in $\mathrm{CO}_{2}$ concentration. Now a near linear correlation is seen between the EO concentration and $\mathrm{SO}_{4}$ coverage for a "clean" catalyst operated in catalytic epoxidation. 


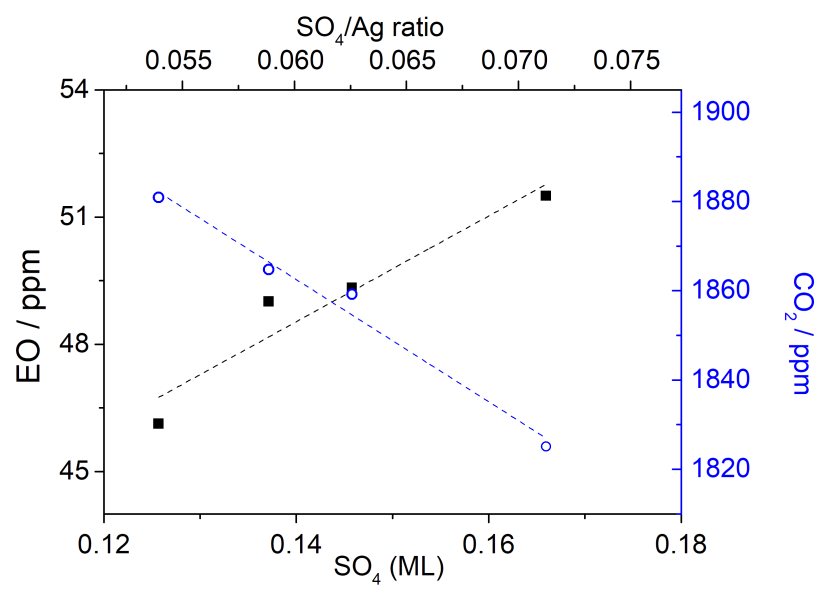

Figure 8: $\mathrm{EO}$ and $\mathrm{CO}_{2}$ production, quantified with a calibrated micro-GC, plotted as a function of the $\mathrm{SO}_{4} / \mathrm{Ag}$ ratio measured by in situ XPS. Tabulated atomic cross sections for photoionization and the related asymmetry parameters were used to normalize the areas obtained from XPS 37,38 . To estimate the $\mathrm{SO}_{4}$ coverage an IMFP of $5.6 \AA$ was used for photoelectrons with $\mathrm{KE}$ of $220 \mathrm{eV}^{39}$ assuming the Ag atomic layers are separated by $2.36 \AA^{24}$.

\section{Conclusions}

In summary, we have shown the methods used to prepare the EOselective oxygen species active on silver catalysts in $\mathrm{TPR}^{9-13}$ - often referred to as electrophilic oxygen-lead to the accumulation of surface $\mathrm{SO}_{4}$, due to sulfur impurities in ethylene and/or silver. On a surface free of coadsorbed oxygen this $\mathrm{SO}_{4}$ forms an unreactive surface reconstruction. When coadsorbed oxygen is present, oxygen induced surface reconstructions are produced, leading to a local competition for silver adatoms that partially lifts the $\mathrm{Ag} / \mathrm{SO}_{4}$ reconstruction. The resulting $\mathrm{SO}_{4}$ adsorbed on the unreconstructed silver surface has the spectroscopic properties associated with $\mathrm{O}_{\text {elec }}$ and produces EO during TPR. DFT calculations suggest $\mathrm{SO}_{4, \text { ad }}$ should be selective in EO production and that the resultant $\mathrm{SO}_{3, \text { ad }}$ can be reoxidized to $\mathrm{SO}_{4, \text { ad }}$ by reaction with $\mathrm{O}_{2}$ or $\mathrm{O}_{\text {ads. }}$ In situ XPS confirms that during catalytic epoxidation $\mathrm{SO}_{4, \text { ad }}$ appears on a clean silver surface under the reaction gas mixture with a coverage that is linearly correlated with 
EO production. We conclude the electrophilic oxygen species appearing at 530.2 $\mathrm{eV}$ in the $\mathrm{O} 1 \mathrm{~s}$ spectrum is the oxygen in $\mathrm{SO}_{4, \text { ad }}$ formed as a result of trace sulfur impurities.

\section{Methods}

Quantum ESPRESSO ${ }^{40}$ was used for DFT calculations at the PBE level with ultrasoft pseudopotentials from the PS library with kinetic energy (charge density) cutoff of $30 \mathrm{Ry}$ (300 Ry) with a $10^{-7}$ convergence threshold for self consistency. Adsorption energies and $\triangle \mathrm{SCF}$ core-level shifts were computed with 5-layer Ag slabs separated by ca. $15 \AA ̊$ vacuum and a $\boldsymbol{k}$-point mesh equivalent to $(12 \times 12)$ for the $(1 \times 1)$ surface unit cell using Marzari-Vanderbilt cold smearing ${ }^{41}$ with a smearing parameter of $0.02 \mathrm{Ry}$. During ionic relaxations the bottom 2 layers of the slab were held fixed and a convergence threshold of $10^{-4}$ Ry (10-3 Ry/Bohr) was used for the total energy (forces). MEPs were computed with the climbing image nudged elastic band method. Transition states were verified by normal mode analysis. Zero-point energy corrections were not included as they changed the results by ca. $0.1 \mathrm{eV}$ at most, see Table S4. Dispersion corrections did not qualitatively alter the results, see Tables S5-S7.

For the experimental portions of the study all samples and analytical techniques to detect EO were chosen based on the limits of the analytical methods and nature of the experiments. These techniques are summarized in Table 1. 
Table 1: Methods used to detect EO production for different samples and experiments.

\begin{tabular}{|l|l|l|}
\hline Sample & Method to detect EO & Corresponding figure \\
\hline Ag(111) & QMS & 4 \\
\hline Ag powder & PTRMS & 6,7 \\
\hline Ag powder & GC & 8 \\
\hline
\end{tabular}

TPR and XPS were performed in a combined UHV/ambient pressure system previously described in detail ${ }^{42}$. The $\mathrm{Ag}(111)$ crystal was cleaned by cycles of $\mathrm{Ar}^{+}$sputtering/heating to $775 \mathrm{~K}$. NO 2 was used for oxidation to avoid high $\mathrm{O}_{2}$ doses $^{43}$, a detailed description of the preparation has been described previously ${ }^{18,19}$. The included XP spectra were measured with a monochromatic $\mathrm{Al} \mathrm{K \alpha}$ source (Omicron XM 1000) and hemispherical analyzer (SPECS Phoibos 100). Spectra were calibrated using the $A g 3 d_{5 / 2}$ peak-BE of $368.25 \mathrm{eV}$. TPR products were measured with a quadrupole mass spectrometer (Pfeiffer Prisma QMS 200 M2). LEED I/V curves were measured at the nanospectroscopy beamline at the synchrotron facility Elettra ${ }^{44}$.

In situ XPS measurements were performed at the near ambient pressure XPS endstation of the ISISS beamline ${ }^{45}$ at the synchrotron facility BESSY II/HZB, Berlin, Germany. Pressed pellets of Sigma-Aldrich Ag powder with a $<100 \mathrm{~nm}$ grain size were used along with ultrahigh purity gases, ethylene 3.6 and oxygen 6.0, obtained from Westfalen. For each in situ XPS experiment a catalyst was mounted on a sapphire sample holder and held in place between two stainless steel plates where the lid had a hole for measuring spectra, see Ref 16 for more details of the approach. Unless otherwise noted, catalyst were cleaned with oxidation/reduction cycles under $0.3 \mathrm{mbar}_{2} / \mathrm{H}_{2}$ at $873 \mathrm{~K}$. Sample temperature 
was measured using a K-type thermocouple squeezed between the sample and the lid while the catalyst was heated from the backside with an IR laser. Temperature was controlled using a PID feedback loop. Gas-phase product quantification was performed with a calibrated Varian Micro-GC CP4900. The gas-phase composition was also continuously measured using a Prisma quadrupole mass spectrometer (QMS) from Balzers and a Proton Transfer Reaction MS (PTRMS) from IONICON Analytik. The latter allows EO to be monitored using $\mathrm{m} / \mathrm{z}=45\left(\mathrm{C}_{2} \mathrm{H}_{4} \mathrm{O}\right.$ and $\left.\mathrm{H}+\right)$, as $\mathrm{CO}_{2}$ does not contribute to the PTRMS signal due to its low proton affinity ${ }^{22}$ and AcH was not observed with the GC in any of the in situ experiments.

\section{Supporting Information}

Table of core level binding energies, measured XPS peak areas, further details of thermodynamic analysis, computed energies at stationary points along the minimum energy paths including dispersion corrections, and minimum energy paths not shown in the main text.

\section{Acknowledgements}

We thank Höchstleistungsrechenzentrum Stuttgart (HLRS) for access to the supercomputer HazelHen through the SEES2 project and Helmholtz-Zentrum Berlin for providing support of the high-pressure electron spectroscopy activities of the FHI at ISISS beamline in BESSY II. T. E. J. acknowledges the Alexander-von-Humboldt Foundation for financial support.

\section{References}


1) van Santen, R. A.; Kuipers, H. P. C. E. The Mechanism of Ethylene Epoxidation. In Advances in Catalysis, Vol. 35; Eley, D. D., Pines, H., Weisz, P. B., Eds.; Academic Press, 1987; pp 265-321.

2) Sachtler, W. M. H.; Backx, C.; van Santen, R. A. On the Mechanism of Ethylene Epoxidation. Catal. Rev. 1981, 23, 127-149.

3) Bukhtiyarov, V. I.; Knop-Gericke, A. Ethylene Epoxidation over Silver Catalysts. In Nanostructured Catalysts: Selective Oxidations; Hess, C., Schlögl, R., Eds.; Cambridge: Royal Society of Chemistry, 2011, pp 214-247.

4) Rebsdat, S.; Mayer, D. Ethylene Oxide. In Ullmann's Encyclopedia of Industrial Chemistry, Vol. 13, Wiley-VCH Verlag GmbH \& Co. KGaA, Weinheim, 2001; pp 547-572.

5) Serafin, J. G.; Liu, A. C.; Seyedmonir, S. R.; Surface science and the silvercatalyzed epoxidation of ethylene: an industrial perspective. J. Mol. Catal. A: Chem. 1998, 131, 157-168.

6) Özbek, M. O.; van Santen, R. A.; The Mechanism of Ethylene Epoxidation Catalysis, Catal. Lett. 2013, 143, 131-141.

7) Diao, W.; DiGiulio, C. D.; Schaal, M. T.; Ma, S.; Monnier, J. R. An investigation on the Role of $\mathrm{Re}$ as a Promoter in $\mathrm{Ag}-\mathrm{Cs}-\mathrm{Re} / \alpha-\mathrm{Al}_{2} \mathrm{O}_{3}$ High-Selectivity, Ethylene Epoxidation Catalysts. J. Catal. 2015, 322, 14-23. 
8) Campbell, C. T. The Selective Epoxidation of Ethylene Catalyzed by $\operatorname{Ag}(111): \mathrm{A}$ Comparison with Ag(110).J. Catal. 1985, 94, 436-444.

9) Backx, C.; Moolhuysen, J.; Geenen, P.; van Santen, R. A. Reactivity of Oxygen Adsorbed on Silver Powder in the Epoxidation of Ethylene. J. Catal. 1981, 72, 364-368.

10) van Santen, R. A.; de Groot, C. P. M. The Mechanism of Ethylene Epoxidation. J. Catal. 1986, 98, 530-539.

11) Grant, R. B.; Lambert, R. M. Mechanism of the Silver-Catalysed Heterogeneous Epoxidation of Ethylene. J. Chem. Soc., Chem. Comm. 1983, 12, 662-663.

12) Bukhtiyarov, V. I.; Boronin, A. I.; Prosvirin, I. P.; Savchenko, V. I. Stages in the Modification of a Silver Surface for Catalysis of the Partial Oxidation of Ethylene: II. Action of the Reaction Medium. J. Catal. 1994, 150, 268-273.

13) Bukhtiyarov, V. I.; Prosvirin, I. P.; Kvon, R. I. Study of Reactivity of Oxygen States Adsorbed at a Silver Surface Towards $\mathrm{C}_{2} \mathrm{H}_{4}$ by XPS, TPD and TPR. Surf. Sci. 1994, 320, L47-L50.

14) Linic, S.; Barteau, M. A. Control of Ethylene Epoxidation Selectivity by Surface Oxametallacycles. J. Am. Chem. Soc. 2003, 125, 4034-4035.

15) Özbek, M. O.; van Santen R. A. The Mechanism of Ethylene Epoxidation Catalysis. Catal. Lett. 2013, 143, 131-141. 
16) Jones, T.; Wyrwich, R.; Böcklein, S.; Rocha, T. C. R.; Carbonio, E. A.; KnopGericke, A.; Schlögl, R.; Günther, S.; Wintterlin, J.; Piccinin, S. Oxidation of Ethylene on Oxygen Reconstructed Silver Surfaces. J. Phys. Chem. C 2016, 120, $28630-28638$.

17) Jones, T. E.; Rocha, T. C. R.; Knop-Gericke, A.; Stampfl, C.; Schlögl, R.; Piccinin, S. Insights into the Electronic Structure of the Oxygen Species Active in Alkene Epoxidation on Silver. ACS Catal. 2015, 5, 5846-5850.

18) Günther, S.; Böcklein, S.; Wintterlin, J.; Niño, M. A.; Menteş, T. O.; Locatelli, A. Locating Catalytically Active Oxygen on Ag(111)—a Spectromicroscopy Study. ChemCatChem 2013, 5, 3342-3350.

19) Böcklein, S.; Günther, S.; Wintterlin, J. High-Pressure Scanning Tunneling Microscopy of a Silver Surface during Catalytic Formation of Ethylene Oxide. Angew. Chem. Int. Ed. 2013, 52, 5518 -5521.

20) Jones, T. E.; Rocha, T. C. R.; Knop-Gericke, A.; Stampfl, C.; Schlögl, R.; Piccinin, S. Thermodynamic and Spectroscopic Properties of Oxygen on Silver Under an Oxygen Atmosphere. Phys. Chem. Chem. Phys. 2015, 17, 9288-9312.

21) Carbonio, E. A.; Rocha, T. C. R.; Klyushin, A. Yu.; Igor Píš, I.; Magnano, E.; Nappini, S.; Piccinin, S.; Knop- Gericke, A.; Schlögl R.; Jones, T. E. Are Multiple Oxygen Species Selective in Ethylene Epoxidation on Silver? Chem. Sci. 2018, 9, 990-998. 
22) Bukhtiyarov, V. I.; Nizovskii, A. I.; Bluhm, H.; Hävecker, M.; Kleimenov, E.;

Knop-Gericke, A.; Schlögl, R. Combined in situ XPS and PTRMS Study of Ethylene Epoxidation Over Silver. J. Catal. 2006, 238, 260-269.

23) Rocha, T. C. R.; Hävecker, M.; Knop-Gericke, A.; Schlögl, R. Promoters in Heterogeneous Catalysis: The Role of $\mathrm{Cl}$ on Ethylene Epoxidation Over Ag. J. Catal. 2014, 312, 12-16.

24) Rocha, T. C. R.; Oestereich, A.; Demidov, D. V.; Hävecker, M.; Zefeiratos, S.; Weinber, G.; Bukhtiyarov, V. I.; Knop-Gericke, A.; Schlögl, R. The Silver-Oxygen System in Catalysis: New Insights by Near Ambient Pressure X-ray Photoelectron Spectroscopy. Phys. Chem. Chem. Phys. 2012, 14, 4554-4564.

25) Schnadt, J.; Michaelides, A.; Knudsen, J.; Vang, R. T.; Reuter, K.; Lægsgaard, E.; Scheffler, M.; Besenbacher, F. Revisiting the Structure of the $p(4 \times 4)$ Surface Oxide on Ag(111). Phys. Rev. Lett. 2006, 96, 146101.

26) Schmid, M.; Reicho, A.; Stierle, A.; Costina, I.; Klikovits, J.; Kostelnik, P.; Dubay, O.; Kresse, G.; Gustafson, J.; Lundgren, E.; Andersen, J. N.; Dosch, H.; Varga, P. Structure of Ag(111)-p(4×4)-0: No Silver Oxide. Phys. Rev. Lett. 2006, 96, 146102.

27) Reichelt, R.; Günther, S.; Wintterlin, J.; Moritz, W.; Aballe, L.; Mentes, T. O. Low Energy Electron Diffraction and Low Energy Electron Microscopy Microspot $I / V$ Analysis of the $(4 \times 4) 0$ Structure on Ag(111): Surface Oxide or Reconstruction? J. Chem. Phys. 2007, 127, 134706. 
28) Zimmermann H.; Walzl, R. Ethylene. In Ullmann's Encyclopedia of Industrial Chemistry, Vol. 13, Wiley-VCH Verlag GmbH \& Co. KGaA, Weinheim, 2009; pp 465-529.

29) Brumby, A.; Braumann, P.; Zimmermann, K.; Francis Van Den Broeck, F.; Vandevelde, T.; Goia, D.; Renner, H.; Schlamp, G.; Zimmermann, K.; Weise, E.; Tews, P.; Dermann, K.; Knödler, A.; Schröder, K.-H.; Kempf, B.; Lüschow, H. M.; Peter, C.; Schiele, R. Silver, Silver Compounds, and Silver Alloys. In: Ullmann's Encyclopedia of Industrial Chemistry, Vol. 33, Wiley-VCH Verlag GmbH \& Co. KGaA, Weinheim, 2008; pp 15-94.

30) Alemozafar, A. R. and Madix, R. J. Surface Reorganization Accompanying the Formation of Sulfite and Sulfate by Reaction of Sulfur Dioxide with Oxygen on Ag(111). J. Chem. Phys. 2005, 122, 214718.

31) Kaushik, V. K. XPS Core Level Spectra and Auger Parameters for some Silver Compounds, J. Elec. Spectrosc. Rela. Phenom. 1991, 56, 273-277.

32) Reuter, K.; Scheffler, M. Composition, Structure, and Stability of $\mathrm{RuO}_{2}(110)$ as a Function of Oxygen Pressure. Phys. Rev. B 2001, 65, 035406.

33) Li, W.X.; Stampfl, C.; Scheffler, M. Insights into the function of silver as an oxidation catalyst by ab initio atomistic thermodynamics. Phys. Rev. B 2003, 68, 165412.

34) Böcklein, S.; Günther, S.; Reichelt, R.; Wyrwich, R.; Joas, M.; Hettstedt, C.; Ehrensperger, M; Sicklinger, J.; Wintterlin, J. Detection and Quantification of 
Steady-State Ethylene Oxide Formation over an Ag(111) Single Crystal. J. Catal. 2013, 299, 129-136.

35) Salem, L.; Rowland, C. The Electronic Properties of Diradicals. Angew. Chem. Int. Ed. 1972, 11, 92-111.

36) Wassmuth, H.-W.; Ahner, J.; Höfer, M.; Stolz, H. Interaction of $\mathrm{SO}_{2}$ with Single Crystal Metal Surfaces. Prog. Surf. Sci. 1993, 42, 257-268.

37) Yeh, J. J. Atomic Calculation of Photoionization Cross-Sections and Asymmetry Parameters; Gordon and Breach Science Publishers: Langhorne, PE (USA), 1993. 38) J.J. Yeh, J. J.; Lindau, L. Atomic Data and Nuclear Data Tables, 1985, 32, 1-155. 39) S. Tanuma, S.; Powell, C. J.; Penn, D. R. Calculations of electron inelastic mean free paths. II. Data for 27 elements over the 50-2000 eV range. Surf. Int. Anal. 1991, 17, 911-926.

40) Giannozzi, P.; Baroni, S.; Bonini, N.; Calandra, M.; Car, R.; Cavazzoni, C.;

Ceresoli, D.; Chiarotti, G. L.; Cococcioni, M.; Dabo, I.; Dal Corso, A.; Fabris, S.;

Fratesi, G.; de Gironcoli, S.; Gebauer, R.; Gerstmann, U.; Gougoussis, C.; Kokalj, A.; Lazzeri, M.; Martin-Samos, L.; Marzari, N.; Mauri, F.; Mazzarello, R.; Paolini, S.;

Pasquarello, A.; Paulatto, L.; Sbraccia, C.; Scandolo, S.; Sclauzero, G.; Seitsonen, A. P.; Smogunov, A.; Umari, P.; Wentzcovitch, R. M. QUANTUM ESPRESSO: A Modular and Open-Source Software Project for Quantum Simulations of Materials. J. Phys.: Condens. Matter 2009, 21, 395502.

41) Marzari, N.; Vanderbilt, D.; De Vita, A.; Payne, M. C. Thermal Contraction and Disordering of the Al(110) Surface. Phys. Rev. Lett. 1999, 82, 3296. 
42) Rößler, M.; Geng, P.; Wintterlin, J. A High-Pressure Scanning Tunneling Microscope for Studying Heterogeneous Catalysis. Rev. Sci. Instrum. 2005, 76, 023705.

43) Bare, S. R.; Griffiths, K.; Lennard, W. N.; Tang, H. T. Generation of Atomic Oxygen on $\mathrm{Ag}(111)$ and $\mathrm{Ag}(110)$ using $\mathrm{NO}_{2}$ : A TPD, LEED, HREELS, XPS and NRA study. Surf. Sci. 1995, 342, 185-198.

44) Locatelli, A.; Aballe, L.; Mentes, T. O.; Kiskinova, M.; Bauer, E. Photoemission Electron Microscopy with Chemical Sensitivity: SPELEEM Methods and Applications. Surf. Interface Anal. 2006, 38, 1554-1557.

45) Knop-Gericke, A.; Kleimenov, E.; Hävecker, M.; Blume, R.; Teschner, D.;

Zafeiratos, S.; Schlögl, R.; Bukhtiyarov, V. I.; Kaichev, V. V.; Prosvirin, I. P.;

Nizovskii, A. I.; Bluhm, H.; Barinov, A.; Dudin, P.; Kiskinova, M. X-Ray

Photoelectron Spectroscopy for Investigation of Heterogeneous Catalytic

Processes. In Advances in Catalysis, Vol. 52; Academic Press, 2009; pp 213-272. 